\title{
Using implicit measures to highlight science teachers' implicit theories of intelligence
}

\author{
Nicolas Mascret • Peggy Roussel • François Cury
}

Received: 8 October 2014 / Revised: 26 January 2015 / Accepted: 23 February 2015 /

Published online: 10 March 2015

(C) Instituto Superior de Psicologia Aplicada, Lisboa, Portugal and Springer Science+Business Media Dordrecht 2015

\begin{abstract}
Using an innovative method, a Single-Target Implicit Association Test (ST-IAT) was created to explore the implicit theories of intelligence among science and liberal arts teachers and their relationships with their gender. The results showed that for science teachers - especially for male teachers - there was a negative implicit association between "intelligence" and "modifiable" stimuli, whereas liberal arts teachers had no implicit association between these two variables. The results are discussed in comparison with previous explicit measures, and the implications for teacher training are highlighted.
\end{abstract}

Keywords Implicit theories of intelligence · Single-target implicit association test - Teachers · Science $\cdot$ Mathematics $\cdot$ Gender

\section{Introduction}

In their review of the literature on attitudes to science, Osborne et al. (2003) identified the many factors of influence such as gender, teachers, curricula and cultural and other variables. Beliefs about intelligence in maths and science domains were considered as influent factors. Implicit theories of intelligence are prominent constructs in contemporary research interested in what individuals think about the nature of intelligence. Implicit theories are personal beliefs or baselines and not necessarily the truth. Two conceptions of the nature of intelligence were highlighted (Dweck 1986, 1999; Dweck and Leggett 1988): "entity theory", in which intelligence is considered innate, stable, like a gift or a talent, and "incremental theory", in which intelligence is considered improvable and depends on effort and work. In the educational context, entity theory was expected to be a negative predictor of students' performance, and incremental theory often results in more adaptive outcomes than entity theory (for reviews, see

N. Mascret $(\bowtie) \cdot$ P. Roussel $\cdot$ F. Cury

Aix Marseille Université, CNRS, ISM UMR 7287, 13288 Marseille, France

e-mail: nicolas.mascret@univ-amu.fr

P. Roussel

e-mail: peggy.roussel@univ-amu.fr

F. Cury

e-mail: francois.cury@univ-amu.fr 
Dweck and Molden 2005; Dweck and Sorich 1999; Good et al. 2003). Numerous studies have been conducted on implicit theories of intelligence among students, and the proposal that entity theory has negative implications for performance has received strong empirical support (e.g. Carr and Dweck 2011; Dweck 1999; Gonida et al. 2006; Stipek and Gralinski 1991). For example, entity theory and incremental theory were respectively negative and positive predictors of maths performance (Cury et al. 2006).

The belief that mathematical intelligence is a fixed trait is a common stereotype (e.g Good et al. 2012; Stipek et al. 2001). It represents a mainstream perspective of the habitual scientific construct of intelligence as innate and fixed (Plaut and Markus 2005). Students believed that those who are capable of doing mathematics were born with a "mathematical gene" (Muis 2004). They believed that ability in mathematics is innate whereas more incremental views of ability in English and social studies were found (Schoenfeld 1989). To study implicit theories of intelligence seemed to be heuristic in an educational context and not only with students, especially in order to identify whether entity and incremental theories were linked with teachers' disciplines. Murrone and Gynther (1991) showed that teachers have implicit theories of intelligence, but these depend on their level of dogmatism and vary according to the context. In general, Calderhead (1996) and Bråten and Stromso (2004) identified the fact that different academic disciplines include different epistemological beliefs about what knowing means. Myers et al. (2003) showed that the teachers' discipline could influence their preferences for either an entity or incremental theory. According to these authors, entity theory could be more frequent in mathematics disciplines. Beach (2003) and Beach and Dovemark (2007) identified the fact that maths skills are often seen to represent an innate ability by maths teachers, and differential performances in maths are felt by mathematics teachers to reflect natural differences in intelligence. Recently, Jonsson et al. (2012) showed that teachers had a significant preference for an incremental theory rather than an entity theory of intelligence. Results were similar with future teachers (Jonsson and Beach 2010). However, the entity theory of intelligence may be more pronounced among teachers of mathematics. The study of implicit theory of intelligence among teachers regardless of their discipline is not currently much developed. To assess teachers' entity and incremental theories of intelligence, several self-reported explicit measures have been developed, like Dweck's (1999) Theories of Intelligence Scale (TIS). But, implicit measures of theories of intelligence do not exist for the moment.

Implicit social cognition is not accessible to conscious introspection. To assess this phenomenon, self-reported measures are not suitable (Greenwald and Banaji 1995). Even if some studies (e.g. Jonsson et al. 2012; Myers et al. 2003) have highlighted the fact that self-reported measures on implicit theories of intelligence identified differences with mathematics and science teachers, one might think that social desirability (e.g. Crosby et al. 1980; Crowne and Marlowe 1960) would inhibit some teachers from explicitly declaring an entity theory of intelligence. Social desirability is the tendency of respondents to answer questions in a manner that will be viewed favourably by others, to present themselves in the best possible light. Subjects' desire to be perceived positively is widely assumed to be a potential source of distortion of self-report measures. For teachers, declaring that intelligence is innate, stable, a gift or a talent should be surprising, because of the objective of the teacher's work that is to enable his pupils to acquire competences, and so to contribute, in part, to the development of their intelligence. The Implicit Association Test (IAT) provides a computer-based measure of the strengths of automatic associations, in order to evaluate implicit cognitive constructs (Greenwald et al. 1998). The IAT measure (or IAT effect) is based on the difference of latencies in 
classifying four categories of stimuli. The basic principle is that it is easier for a subject to pair concepts (e.g. flower) with attributes (e.g. pleasant attributes like wonderful, happy) usually associated with them in his own experience. It is more difficult to pair the concept "flower" with unpleasant attributes (e.g. disgust, hatred, gun), whereas it is easier to pair these unpleasant attributes with another concept (e.g. insect). So, IAT measures the latency of association of stimuli (words, images) in a compatible condition (like "flower-pleasant" and "insect-unpleasant") compared with an incompatible condition (like "flower-unpleasant" and "insect-pleasant"). Ease or strength of implicit association is measured by the speed of response to one type of pairing compared with another type. The presence and nature of the second contrasting category can shape the attitude that is revealed (Nosek and Banaji 2001). IAT is heuristic for measuring implicit social cognition especially in the domains of attitudes, stereotypes and identity (Greenwald et al. 2002; Greenwald et al. 2003).

To our knowledge, there was only one IAT linked to implicit theories of intelligence (Fujii and Uebuchi 2010), in Japanese. The target concepts were intelligence and luck, so, this IAT measured whether individuals associated their results more strongly with one than the other. Hence, this IAT did not really measure implicit theories of intelligence, such as entity or incremental theories (Dweck 1986, 1999; Dweck and Leggett 1988). Another IAT (Dislich et al. 2012) highlighted implicit self-concepts of intelligence, but not really the implicit theories. These two IAT about intelligence were not used with teachers. A problem soon arose with the concept of intelligence: in the IAT procedure, many attitude objects had a complementary category (Greenwald and Farnham 2000), and it was interesting to compare one with the other (e.g. positive-negative, self-other, male-female, young-old), but this was not the case for the concept of intelligence. The IAT cannot reveal the evaluative associations with a single-target concept (Karpinski and Steinman 2006). So, based on the theoretical framework of IAT, Karpinski and Steinman created the Single Category Implicit Association Test (SC-IAT). The SC-IAT is conceptually identical to the Single-Target IAT (ST-IAT; Bluemke and Friese 2008; Wigboldus et al. 2004) and had only minor procedural differences: the ST-IAT included an initial practice stage with only good and bad target words, had fewer target words in each stage and did not use a response window for slow answers (Karpinski and Steinman 2006). For the moment, no IAT, ST-IAT or SC-IAT existed to identify implicit theories of intelligence.

The first aim of our study was to create an IAT which could highlight whether individuals adhered to an entity theory (intelligence is more stable than modifiable) or an incremental theory (intelligence is more modifiable than stable). The second aim was to use this implicit measure with science and liberal arts teachers, in order to identify whether there were differences in teachers' conceptions of intelligence according to their academic discipline.

\section{Method}

\section{Participants}

Data were collected from ten French lower secondary schools (students aged 11-15) in the greater Marseille area. Permission was granted by the school principal to contact teachers directly. Sixty volunteer teachers $(21$ male, 39 female, mean age $=27.78)$ in several academic disciplines - mathematics (16) and biology (14), categorized as 
"science" and French (14) and history (16), categorized as "liberal arts"-voluntarily participated in the study. Each participant completed the ST-IAT individually.

Stimuli and pilot test

Twenty-five nouns were selected by a first 20 pilot French teacher sample in order to create the lexical stimuli: seven "stable" words, seven "modifiable" words and nine "intelligence" words. Subsequently, the words were rated in a first step by a second 125 pilot teacher sample (mathematics, biology, French and history teachers) for their degree of link with "stable," "modifiable" and "intelligence" on a 5-point scale (1=not at all, 5=extremely). The five words with the most extreme evaluation for each category were retained. For "stable" and "modifiable" stimuli, word length was controlled by counting the numbers of letters, and there were no significant differences $(t(8)=-.53, p=.61)$ between "stable" words $(M=9.2, \mathrm{SD}=1.64)$ and "modifiable" words $(M=9.8, \mathrm{SD}=1.92)$. In a second phase, the words were rated by the same sample for the degree to which they were "stable" related or "modifiable" related on a 5-point scale ( $1=$ strongly linked to "stable", $3=$ neither "stable" linked nor "modifiable" linked, 5= strongly linked to "modifiable"). The "stable" words were rated as more "stable" related $(M=$ $1.98, \mathrm{SD}=1.22)$ than the "modifiable" words, and the "modifiable" words were rated as more "modifiable" related $(M=4.32, \mathrm{SD}=0.92)$ than "stable" words. Based on these ratings, fifteen words were selected and used as lexical stimuli in the ST-IAT (see Appendix): five "stable" words (consistent, balanced, stationary, immobile, permanent), five "modifiable" words (mutable, convertible, malleable, progressive, adaptable) and five "intelligence" words (understanding, capacity, skill, aptitude, discernment). Decisions about the number of stimuli to use for an IAT can be based on pragmatic concerns, with at least four stimulus items per category appearing to be ideal but two items per category being sufficient (Nosek, Greenwald and Banaji, 2005).

\section{Design and procedure}

Participants were tested alone each time. Each participant was seated at a desk with a personal computer with a 15-in. monitor using Inquisit 3 software. Following the ST-IAT procedure (Bluemke and Friese, 2008), the measure design consisted of 80 trials divided into two combined blocks. Participants started with a training block (20 trials) for the evaluative words prior to each combined block. Each stimulus was presented at least twice, adding up to 40 trials per combined block. Participants placed one finger on the $E$ key (the left key) of the keyboard and another finger on the $I$ key (the right key). "Intelligence" words were the target concept, and stable and "modifiable" words were the attribute concepts. In the training blocks, they were instructed to respond by pressing a key (e.g. the left key) each time an item that represented the category stable (e.g. immobile, permanent) appeared in the centre of the screen, or the other key (e.g. the right key) each time an item that represented the category modifiable (e.g. adaptable, mutable) appeared. Then the category intelligence only appeared on one side of the computer screen, and subjects were instructed to respond by pressing the appropriate key (left or right) when an item linked with intelligence (e.g. aptitude, understanding) appeared in the centre of the screen. For the other half of the task, the target concept was switched to the other key. The difference in response latency between the average speed of response to "intelligence" and stable items when they were paired together, and the average speed of response to "intelligence" and "modifiable" items when they were paired together was analysed. 
Based on Greenwald et al. (2003), ST-IAT scores were computed by using the $D$-score algorithm for the ST-IAT data (Bluemke and Friese 2006, 2008). Following these authors, responses less than $300 \mathrm{~ms}$, responses more than $3000 \mathrm{~ms}$ and nonresponses were eliminated. The average response times of the first combined block (e.g. stable-intelligence) were subtracted from the average response times of the second combined block (e.g. modifiable - intelligence). This quantity was divided by the standard deviation of all correct response times within the first and the second combined blocks, using only responses to critical trials. Classically, data from participants who had an error rate of greater than $20 \%$ on the ST-IAT are removed from analyses. This was not the case in our study; consequently, all participants were included in the results.

\section{Results}

Preliminary results

One-way ANOVA comparing ST-IAT scores for science teachers according to their academic discipline (mathematics versus biology) was not significant $(F(1,28)=.07, p=.80)$. Another one-way ANOVA comparing ST-IAT scores for liberal arts teachers according to their academic discipline (French versus history) was not significant $(F(1,28)=.47, p=.83)$. Moreover, data analysis revealed equal variance between the four discipline groups concerning the ST-IAT score (Hartley $F_{\max }=2.85, p=.31$ ). Consequently, responses from teachers of mathematics and biology were categorized as "science teachers' scores" $(n=30)$, and responses from teachers of French and history were categorized as "liberal arts teachers' scores" $(n=30)$.

\section{Main results}

According to the Implicit Association Test analysis (e.g. Bluemke and Friese 2008; Greenwald et al. 2003; Karpinski and Steinman 2006), the ST-IAT revealed no significant association $(D=$ -0.04 ) between intelligence and attributes tested ("stable" and "modifiable") for all teachers, whatever their academic discipline. Separate analyses revealed for science teachers a negative slight to medium-sized association between "intelligence" and "modifiable" $(D=-0.20)$ compared with "stable". The IAT is assumed to be a measure of the relative strength of association between concept-attribute pairs (Nosek et al. 2005); consequently, our results evidenced the fact that science teachers have a stronger negative automatic association between "intelligence" and "modifiable" than between "intelligence" and "stable", but the results did not necessarily mean that the association between "intelligence" and "modifiable" was rejected by science teachers. No significant association $(D=0.12)$ was found between "intelligence" and "modifiable" for liberal arts teachers.

An ANOVA conducted on ST-IAT score revealed (1) a significant effect of type of discipline $\left(F(1,56)=16.83, p<.001, \eta_{p}{ }^{2}=.23\right)$, evidencing that science teachers obtained a higher negative implicit association between "intelligence" words and "modifiable" words $(M=-0.20, \mathrm{SD}=0.36)$ than liberal arts teachers $(M=0.12, \mathrm{SD}=0.27) ;(2)$ a nearly significant effect of gender $\left(F(1,56)=3.95, p=.052, \eta_{p}{ }^{2}=.07\right)$, indicating that male teachers tended to obtain a higher negative implicit association between "intelligence" words and "modifiable" words $(M=-0.22, \mathrm{SD}=0.43)$ than female teachers $(M=0.05, \mathrm{SD}=0.27)$; and (3) a significant interaction between the two independent variables $\left(F(1,56)=6.52, p<.02, \eta_{p}{ }^{2}=.10\right)$.

Newman-Keuls analyses evidenced the fact that male science teachers obtained a higher negative implicit association between "intelligence" words and "modifiable" words $(M=$ 
$-0.41, \mathrm{SD}=0.38)$ than male liberal arts teachers $(M=0.15, \mathrm{SD}=0.24, p<.001)$; on the other hand, no significant differences were observed between female science teachers $(M=0.03$, $\mathrm{SD}=0.25)$ and female liberal arts teachers $(M=0.11, \mathrm{SD}=0.29, p=0.28)$ for an implicit association between "intelligence" words and "modifiable" words. Furthermore, male science teachers obtained a higher negative implicit association between "intelligence" words and "modifiable" words $(M=-0.41, \mathrm{SD}=0.38)$ than female teachers in science disciplines $(M=$ $0.03, \mathrm{SD}=0.25, p<.003)$; by contrast, no significant differences were found between male liberal arts teachers $(M=0.15, \mathrm{SD}=0.24)$ and female liberal arts teachers $(M=0.11, \mathrm{SD}=0.29$, $p=0.69$ ).

\section{Discussion}

Our study used a Single Category Implicit Association Test in order to identify teachers' implicit theories of intelligence according to their discipline. The three main results of the study showed that with implicit measures, (1) for science teachers, there was a negative implicit association between "intelligence" and "modifiable", compared with "stable"; (2) liberal arts teachers had no implicit association between these two variables; and (3) male science teachers had a higher negative association between "intelligence" and "modifiable" than other teachers (female science teachers and liberal arts teachers, regardless of their gender).

Firstly, compared with liberal arts teachers, science teachers had a negative implicit association between "intelligence" and "modifiable". Previous studies conducted in the education domain with explicit measures (Beach 2003; Beach and Dovemark 2007; Bråten and Stromso 2004; Jonsson et al. 2012; Myers, Nichols and White 2003) showed that intelligence was more often considered by science teachers as innate and stable than by other teachers. The results of the implicit measures used with teachers in our study were in line with previous explicit results. One of the central topics for research on unconscious processes is the link between implicit and explicit measures (e.g. Banaji et al. 2001; Greenwald and Banaji 1995; Greenwald et al. 2009). The first works on this relationship showed that the unconscious and the conscious might proceed independently and were not related (Banaji and Greenwald 1994; Banaji and Hardin 1996). Thereafter, several studies showed that the correlation could vary from weak to strong and that explicit and implicit measures could be positively associated (e.g. Cunningham et al. 2001; Hofmann et al. 2005; Lepore and Brown 1997; Nosek et al. 2002b). Implicitly, science teachers have negatively associated "intelligence" and "modifiable" words. The IAT was based on the fact that it ought to be easier to make the same behavioural response (a key press) to concepts that are strongly associated than to concepts that are weakly associated (Greenwald et al. 1998). In contrast to the liberal arts teachers, it was easier for the science teachers to associate "intelligence" with "stable" words than "modifiable" words, evidencing that they were more likely to endorse entity theory than other teachers, as in the results of the studies using explicit measures. However, in Jonsson et al.'s (2012) study, teachers in mathematics and science did not differ from other teachers in their preference between entity and incremental theories of intelligence. Explicit incremental scores were always higher for all teachers than entity scores, even if, as seen previously, entity scores were higher for science teachers than those for the others. Implicit measures evidenced the fact that this was not the case in our study. The results of the ST-IAT showed that teachers in science disciplines obtained a higher negative implicit association between "intelligence" words and "modifiable" words than with "stable" words, which was in line with adherence to an entity theory. In explicit measures, social desirability would deter some teachers from explicitly declaring an entity theory of intelligence, which partly explained why explicit incremental scores are always higher than entity scores for 
teachers as a whole, regardless of their disciplines (Jonsson et al. 2012). In implicit measures, the results of our study evidenced that there was no automatic and implicit association between "intelligence" and "modifiable" for all the teachers who participated in the study, and a negative slight to medium-sized implicit association for science teachers. Measures of implicit cognition differed from self-report in that they can reveal mental associations without requiring an act of introspection (Nosek et al. 2005). Because IAT is a relative measure, incremental theory was not rejected by science teachers in implicit measures, but an implicit association between "intelligence" and "stable" was stronger than between "intelligence" and "modifiable", contrary to explicit measures. Furthermore, in Jonsson et al.'s (2012) explicit study, the teachers in social science and practical disciplines had significantly stronger belief in incremental theories and less belief in entity theories. In our research, no significant implicit association was found for liberal arts teachers between "intelligence" and "modifiable", or between "intelligence" and "stable". However, according to the Implicit Association Test analysis (e.g. Bluemke and Friese 2008; Greenwald et al. 2003; Karpinski and Steinman 2006), the ST-IAT score of our study revealed for liberal arts teachers a nearly significant positive association between "intelligence" and "modifiable". So, the tendency was similar for liberal arts teachers in explicit and implicit studies.

Our study also showed that male science teachers are more likely to have a higher negative implicit association between "intelligence" and "modifiable" than other teachers (female science teachers and liberal arts teachers, regardless of their gender). Whereas there was no significant difference in terms of mathematical performance between men and women (ElseQuest et al. 2010; Lindberg et al. 2010), science and maths aspirations and achievement were influenced by the stereotype that in general, men are naturally more gifted and interested in these areas than women (e.g. Frome and Eccles 1998; Kiefer and Sekaquaptewa 2007; Li 1999). Consequently, male science teachers were likely to consider that intelligence is stable because their implicit theory of intelligence was in line with the initial stereotype that men were naturally good at mathematics and science rather than women. Good et al. (2012) highlighted that the sense of belonging to maths (i.e. one's feelings of membership and acceptance in the maths domain) was a new factor and a new scale that can explain differences between men and women in this domain. The maths ability stereotype (maths intelligence is a fixed trait) and the maths gender stereotype (women underperform rather than men in maths) affected women's sense of belonging to maths (but not men's), their maths grades and their desire to pursue maths in the future. The maths gender stereotype was also studied with IAT (e.g. Cvencek et al. 2011; Kiefer and Sekaquaptewa 2007; Liu et al. 2010; Nosek et al. 2002a, b; Nosek et al. 2009; Park et al. 2001) and confirmed the previous explicit results. If they are now science teachers, females who participated in our study should think that hard work and training were necessary to overcome the stereotype that science is a male field, which would allow us to suppose that they did not have an implicit association between "intelligence" and "stable" in the ST-IAT.

When science teachers themselves adhered to an entity theory of intelligence, they might intentionally or unintentionally activate the stereotype that maths-science intelligence is fixed, innate or a gift. Addressing this latter issue and identifying implicit theories of intelligence with implicit measures like the ST-IAT used in our study were important with regard to the educational context. Indeed, teacher beliefs seemed to be taken over by the pupils through feedback connections (e.g. Rosenthal and Jacobson 1992) and affected their performances on learning tasks. Teachers who considered maths ability to be a fixed trait perceived themselves to be less effective and had stronger needs to control student behaviour than did teachers who believed that maths ability can readily change (Midgley et al. 1988). Trouilloud et al. (2006) identified the fact that teachers had stronger tendencies toward creating a competitive climate in class when they pursued entity theory. They were also likely to have performance-avoidance 
goals which are often deleterious for teaching efficacy (Shim, Cho and Cassady 2013). This kind of teachers seemed to promote their pupil's inner motivational resources less well than teachers who followed incremental theory (Leroy et al. 2007). Rattan et al. (2012) study was the first to investigate the relations between the implicit theories of intelligence and the instructional practices of mathematics instructors and teachers when students had difficulties. They observed that teachers who endorse entity theory tended to confirm students in their low ability when they failed (e.g. part of the paper's title: "It's ok - Not everyone can be good at math"), and they explained their failure by a lack of maths intelligence. So, this kind of teachers confirmed students in their maths stereotype, and even demotivated them, because participants in entity conditions endorsed a significantly more fixed belief about maths intelligence than those in the incremental theory condition. This result is very interesting for understanding the consequences of teachers' instructional practices, in order to increase students' success at school. Indeed, some studies show that adult entity theorists often diagnose people's stable traits (which is not the best way to increase students' skills), whereas incremental theorists think that people can progressively change (e.g. Butler 2000; Plaks et al. 2001).

Limitations and directions for future studies can be envisaged. The ST-IAT was found to be a valid and reliable measure of implicit social cognition (Bluemke and Friese 2008). It measures the evaluation of a target object without the need to simultaneously evaluate a counter-category, as in original IAT method. The choice between IAT and ST-IAT depends on the research question, and the ST-IAT seems more beneficial when a naturally opposing category is unavailable (Bluemke and Friese 2008). ST-IAT may improve chances for obtaining higher criterion correlations. However, the ST-IAT could be suggested to provide ambiguous answers, because it could be considered as an absolute evaluation of the target concept (i.e. intelligence in the present study). But, the ST-IAT did not simply measure a general evaluation of intelligence. No attitude can be measured in absolute terms; all attitudes need a comparative judgement. Following Karpinski and Steinman (2006), ST-IAT or SC-IAT can be used to eliminate one comparative dimension but not both of the comparative dimensions. There is in the present study a culturally complementary comparison (men $v s$ women) and a discipline-based one (liberal arts vs science). These categories could be discussed. Only based on a sex categorization in our work, the feminine and masculine gender (Bem 1974) of the teachers could also be identified. Concerning disciplines, further pairwise comparisons could provide a more accurate picture, as social class, age, kind of teacher training, years of experience or type of school. But, the actual sample size was quite small to include these variables. We based the present study only on the distinction between science and liberal arts disciplines, following Nosek et al. (2002a) work. Future studies using implicit measures may incorporate other variables to seek higher understanding of teachers' beliefs about intelligence.

\section{Conclusion}

Our study showed with implicit measures that male science teachers are more likely to endorse the entity theory of intelligence than female science teachers and liberal arts teachers, regardless of their gender. Implicit theory of intelligence can now be identified with classic self-reported measures and implicit measures with ST-IAT, in order to control for the social desirability that can potentially be attached to teachers' conceptions of intelligence. Even if it has been suggested that implicit theories of intelligence were hard to change in initial teacher education (Pajares 1992), it is an important issue, because Deemer (2004) showed how teachers' beliefs about teaching and learning influenced their instructional practices and students' goals in the classroom. 


\section{Appendix}

Table 1 Terms used in the implicit theories of intelligence ST-IAT (translated from French)

\begin{tabular}{lll}
\hline Intelligence & Stable & Modifiable \\
\hline Understanding & Consistent & Mutable \\
Capacity & Balanced & Convertible \\
Skill & Stationary & Malleable \\
Aptitude & Immobile & Progressive \\
Discernment & Permanent & Adaptable \\
\hline
\end{tabular}

\section{References}

Banaji, M., \& Greenwald, A. G. (1994). Implicit stereotyping and prejudice. In M. P. Zanna \& J. M. Olson (Eds.), The Psychology of prejudice: The Ontario symposium (Vol. 7, pp. 55-76). Hillsdale, NJ: Erlbaum.

Banaji, M. R., \& Hardin, C. D. (1996). Automatic stereotyping. Psychological Science, 7(3), 136-141.

Banaji, M. R., Lemm, K. M., \& Carpenter, S. J. (2001). The social unconscious. In A. Tesser \& N. Schwarz (Eds.), Blackwell handbook of social psychology (Intraindividual processes, Vol. 1, pp. 134-158). Malden, MA: Blackwell.

Beach, D. (2003). Mathematics goes to market. In D. Beach, T. Gordon, \& E. Lahelma (Eds.), Democratic education - ethnographic challenges. London: Tufnell Press.

Beach, D., \& Dovemark, M. (2007). Education and the commodity problem: ethnographic investigations of creativity and performativity in Swedish schools. London: Tufnell Press.

Bem, S. L. (1974). The measurement of psychological androgyny. Journal of Consulting and Clinical Psychology, 42(2), 155-162.

Bluemke, M., \& Friese, M. (2006). Do features of stimuli influence IAT effects? Journal of Experimental Social Psychology, 42, 163-176.

Bluemke, M., \& Friese, M. (2008). Reliability and validity of the Single-Target IAT (ST-IAT): assessing automatic affect towards multiple attitude objects. European Journal of Social Psychology, 38(6), 977-997.

Bråten, I., \& Stromso, H. I. (2004). Epistemological beliefs and implicit theories of intelligence as predictors of achievement goals. Contemporary Educational Psychology, 29(4), 371-388.

Butler, R. (2000). Making judgments about ability: the role of implicit theories of ability in moderating inferences from temporal and social comparison information. Journal of Personality and Social Psychology, 78, 965-978.

Calderhead, J. (1996). Teachers: beliefs and knowledge. In D. C. Berliner \& R. C. Calfee (Eds.), Handbook of educational psychology (pp. 709-725). New York: Macmillan.

Carr, P. B., \& Dweck, C. S. (2011). Intelligence and motivation. In R. J. Sternberg \& S. B. Kaufman (Eds.), The Cambridge handbook of intelligence (pp. 748-770). New York, NY: Cambridge University Press.

Crosby, F., Bromley, S., \& Saxe, L. (1980). Recent unobtrusive studies of black and white discrimination and prejudice: a literature review. Psychological Bulletin, 87, 546-563.

Crowne, D. P., \& Marlowe, D. (1960). A new scale of social desirability independent of psychopathology. Journal of Consulting Psychology, 24, 349-354.

Cunningham, W. A., Preacher, K. J., \& Banaji, M. R. (2001). Implicit attitude measures: consistency, stability, and convergent validity. Psychological Science, 12(2), 163-170.

Cury, F., Elliot, A. J., Da Fonseca, D., \& Moller, A. C. (2006). The social-cognitive model of achievement motivation and the $2 \times 2$ achievement goal framework. Journal of Personality and Social Psychology, 90, 666-679.

Cvencek, D., Andrew, N., Meltzoff, A. N., \& Greenwald, A. G. (2011). Math-gender stereotypes in elementary school children. Child Development, 82(3), 766-779.

Deemer, S. A. (2004). Classroom goal orientation in high school classrooms: revealing links between teacher beliefs and classroom environments. Educational Research, 46, 73-90. 
Dislich, F. X. R., Imhoff, R., Banse, R., Altstötter-Gleich, C., Zinkernagel, A., \& Schmitt, M. (2012). Discrepancies between implicit and explicit self-concepts of intelligence predict performance on tests of intelligence. European Journal of Personality, 26, 212-220.

Dweck, C. S. (1986). Motivational processes affecting learning. American Psychologist, 41, 1040-1048.

Dweck, C. S. (1999). Self-theories: their role in motivation, personality, and development. Philadelphia: Psychology Press.

Dweck, C. S., \& Leggett, E. (1988). A social-cognitive approach to motivation and personality. Psychological Review, 95, 256-273.

Dweck, C. S., \& Molden, D. C. (2005). Self-theories: their impact on competence motivation and acquisition. In A. Elliot \& C. S. Dweck (Eds.), The Handbook of competence and motivation (pp. 122-140). New York: Guilford Press.

Dweck, C. S., \& Sorich, L. (1999). Mastery-oriented thinking. In C. R. Snyder (Ed.), Coping (pp. 232-251). New York: Oxford University Press.

Else-Quest, N. M., Hyde, J. S., \& Linn, M. C. (2010). Cross-national patterns of gender differences in mathematics: a meta-analysis. Psychological Bulletin, 136, 103-127.

Frome, P. M., \& Eccles, J. S. (1998). Parents' influence on children's achievement-related perceptions. Journal of Personality and Social Psychology, 74, 435-452.

Fujii, T., \& Uebuchi, H. (2010). Assessment of participants' theories of intelligence: reliability and validity of the implicit association test. Japanese Journal of Educational Psychology, 58(3), 263-274.

Gonida, E., Kosseoglou, G., \& Leondari, A. (2006). Implicit theories of intelligence, perceived academic competence, and school achievement: testing alternative models. American Journal of Psychology, 119(2), 223-238.

Good, C., Aronson, J., \& Inzlicht, M. (2003). Improving adolescents' standardized test performance: an intervention to reduce the effects of stereotype threat. Journal of Applied Developmental Psychology, 24, 645-662.

Good, C., Rattan, A., \& Dweck, C. S. (2012). Why do women opt out? Sense of belonging and women's representation in mathematics. Journal of Personality and Social Psychology, 102(4), 700-717.

Greenwald, A. G., \& Banaji, M. R. (1995). Implicit social cognition: attitudes, self-esteem, and stereotypes. Psychological Review, 102, 4-27.

Greenwald, A. G., \& Farnham, S. D. (2000). Using the implicit association test to measure self-esteem and selfconcept. Journal of Personality and Social Psychology, 79, 1022-1038.

Greenwald, A. G., Banaji, M. R., Rudman, L. A., Farnham, S. D., Nosek, B. A., \& Mellott, D. S. (2002). A unified theory of implicit attitudes, stereotypes, self-esteem, and self-concept. Psychological Review, 109, 3-25.

Greenwald, A. G., McGhee, D. E., \& Schwartz, J. L. K. (1998). Measuring individual differences in implicit cognition: the implicit association test. Journal of Personality and Social Psychology, 74, 1464-1480.

Greenwald, A. G., Nosek, B. A., \& Banaji, M. R. (2003). Understanding and using the implicit association test: I. An improved scoring algorithm. Journal of Personality and Social Psychology, 85, 197-216.

Greenwald, A. G., Poehlman, T. A., Uhlmann, E. L., \& Banaji, M. R. (2009). Understanding and using the implicit association test: III. Meta-analysis of predictive validity. Journal of Personality and Social Psychology, 97(1), 17-41.

Hofmann, W., Gawronski, B., Gschwendner, T., Le, H., \& Schmitt, M. (2005). A meta-analysis on the correlation between the implicit association test and explicit self-report measures. Personality and Social Psychology Bulletin, 31(10), 1369-1385.

Jonsson, A. C., \& Beach, D. (2010). Reproduction of social class in teacher education: the influence of scientific theories on future teachers' implicit beliefs. Journal for Critical Education Policy Studies, 8(2).

Jonsson, A. C., Beach, D., Korp, H., \& Erlandson, P. (2012). Teacher's implicit theories of intelligence: influences from different disciplines and scientific theories. European Journal of Teacher Education, 35(4), 387-400.

Karpinski, A., \& Steinman, R. B. (2006). The single category implicit association test (SC-IAT) as a measure of implicit social cognition. Journal of Personality and Social Psychology, 91, 16-32.

Kiefer, A. K., \& Sekaquaptewa, D. (2007). Implicit stereotypes, gender identification, and math-related outcomes: a prospective study of female college students. Psychological Science, 18, 13-18.

Lepore, L., \& Brown, R. (1997). Category and stereotype activation: is prejudice inevitable? Journal of Personality and Social Psychology, 72(2), 275.

Leroy, N., Bressoux, P., Sarrazin, P., \& Trouilloud, D. (2007). Impact of teachers' implicit theories and perceived pressures on the establishment of an autonomy supportive climate. European Journal of Psychology of Education, 22(4), 529-545.

Li, Q. (1999). Teachers' beliefs and gender differences in mathematics: a review. Educational Research, 41, 63-76.

Lindberg, S. M., Hyde, J. S., Petersen, J. L., \& Linn, M. C. (2010). New trends in gender and mathematics performance: a meta-analysis. Psychological Bulletin, 136, 1123-1135.

Liu, M., Hu, W., Jiannong, S., \& Adey, P. (2010). Gender stereotyping and affective attitudes towards science in Chinese secondary school students. International Journal of Science Education, 32(3), 379-395.

Midgley, C., Feldlaufer, H., \& Eccles, J. (1988). The transition to junior high school: beliefs of pre-and posttransition teachers. Journal of Youth and Adolescence, 17, 543-562. 
Muis, K. R. (2004). Personal epistemology and mathematics: a critical review and synthesis of research. Review of Educational Research, 74(3), 317-377.

Murrone, J., \& Gynther, M. (1991). Teachers' implicit "theories" of children's intelligence. Psychological Reports, 69, 1195-1201.

Myers, M. D., Nichols, J. D., \& White, J. (2003). Teacher and student incremental and entity views of intelligence. The effects of self-regulation and persistence activities. International Journal of Educational Reform, 12(2), 97-117.

Nosek, B. A., \& Banaji, M. R. (2001). The go/no-go association task. Social Cognition, 19, 625-664.

Nosek, B. A., Banaji, M. R., \& Greenwald, A. G. (2002a). Math=male, me $=$ female, therefore math $\neq$ me. Journal of Personality and Social Psychology, 83(1), 44-59.

Nosek, B. A., Banaji, M. R., \& Greenwald, A. G. (2002b). Harvesting implicit group attitudes and beliefs from a demonstration web site. Group Dynamics: Theory, Research, and Practice, 6(1), 101-115.

Nosek, B. A., Greenwald, A. G., \& Banaji, M. R. (2005). Understanding and using the implicit association test: II. Method variables and construct validity. Personality and Social Psychology Bulletin, 31(2), 166-180.

Nosek, B. A., Smyth, F. L., Sriram, N., Lindner, N. M., Devos, T., Ayala, A., et al. (2009). National differences in gender-science stereotypes predict national sex differences in science and math achievement. Proceedings of the National Academy of Sciences, USA, 106, 10593-10597.

Osborne, J., Simon, S., \& Collins, S. (2003). Attitudes towards science: a review of the literature and its implications. International Journal of Science Education, 25(9), 1049-1079.

Pajares, M. F. (1992). Teachers' beliefs and educational research: cleaning up a messy construct. Review of Educational Research, 62(3), 307-332.

Park, L. E., Cook, K. E., \& Greenwald, A. G. (2001). Implicit indicators of women's persistence in math, science, and engineering. Psi Chi Journal of Undergraduate Research, 6, 145-152.

Plaks, J. E., Stroessner, S. J., Dweck, C. S., \& Sherman, J. W. (2001). Person theories and attention allocation: preferences for stereotypic versus counterstereotypic information. Journal of Personality and Social Psychology, 80, 876-893.

Plaut, V. C., \& Markus, H. R. (2005). The "inside" story: a cultural-historical analysis of being smart and motivated, American style. In A. J. Elliot \& C. S. Dweck (Eds.), Handbook of competence and motivation (pp. 457-488). New York: Guilford Press.

Rattan, A., Good, C., \& Dweck, C. S. (2012). "It's ok-Not everyone can be good at math": instructors with an entity theory comfort (and demotivate) students. Journal of Experimental Social Psychology, 48, 731-737.

Rosenthal, R., \& Jacobson, L. (1992). Pygmalion in the classroom. New York: Irvington.

Schoenfeld, A. H. (1989). Explorations of students' mathematical beliefs and behavior. Journal for Research in Mathematics Education, 20, 338-355.

Shim, S. S., Cho, Y. J., \& Cassady, J. (2013). Goal structure: the role of teacher's achievement goals and theories of intelligence. The Journal of Experimental Education, 81(1), 84-104.

Stipek, D. J., Givvin, K. B., Salmon, J. M., \& MacGyvers, V. L. (2001). Teachers' beliefs and practices related to mathematics instruction. Teaching and Teacher Education, 17(2), 213-226.

Stipek, D., \& Gralinski, H. (1991). Gender differences in children's achievement-related beliefs and emotional responses to success and failure in mathematics. Journal of Educational Psychology, 83, 361-371.

Trouilloud, D., Sarrazin, P., \& Bois, J. (2006). Teacher expectation effects on student perceived competence in physical education classes: autonomy-supportive climate as a moderator. Journal of Educational Psychology, 98(1), 75-86.

Wigboldus, D. H. J., Holland, R. W., \& van Knippenberg, A. (2004). Single target implicit associations. Unpublished manuscript.

\section{Authors' information}

Nicolas Mascret. Aix Marseille Université, CNRS, ISM UMR 7287, 13288, Marseille, France. Email: nicolas.mascret@univ-amu.fr

Current themes of research:

Implicit theories. Achievement goals. Reciprocal Peer Tutoring.

Most relevant publications in the field of Psychology of Education:

Mascret, N. (2011). "Badminton player-coach" interactions between failing students. Physical Education and Sport Pedagogy, 16(1), 1-13. 
Mascret, N., Elliot, A. J., \& Cury, F. (2015). Extending the $3 \times 2$ achievement goal model to the sport domain: The $3 \times 2$ Achievement Goal Questionnaire for Sport. Psychology of Sport and Exercise, 17, 7-14.

Maïano, C. Morin, A. J. S., \& Mascret, N. (2015). Psychometric properties of the short form of the physical selfdescription questionnaire in a French adolescent sample. Body Image, 12, 89-97. doi: 10.1016/j.bodyim. 2014.10.005.

Roussel Peggy. Aix Marseille Université, CNRS, ISM UMR 7287, 13288, Marseille, France. Email: peggy.roussel@univ-amu.fr

Current themes of research:

Achievement goals. Help-seeking.

Most relevant publications in the field of Psychology of Education:

Roussel, P., Elliot, A. J., \& Feltman, R. (2011). The influence of achievement goals and social goals on help-seeking from peers in an academic context. Learning and Instruction, 21(3), 394-402.

Cury François. Aix Marseille Université, CNRS, ISM UMR 7287, 13288, Marseille, France. Email: francois.cury@univ-amu.fr

Current themes of research:

Achievement goals. Implicit theories.

Most relevant publications in the field of Psychology of Education:

Cury, F., Da Fonséca, D., Zahn, I., \& Elliot, A. (2008). Implicit theories and IQ test performance: A sequential mediational analysis. Journal of Experimental Social Psychology, 44 (3), 783-791.

Cury, F., Elliot, A. J., Da Fonseca, D., \& Moller, A. C. (2006). The social-cognitive model of achievement motivation and the $2 \times 2$ achievement goal framework. Journal of Personality and Social Psychology, 90(4), 666.

Da Fonséca, D., Cury, F., Fakra, E., Rufo, M., Poinso, F., Bounoua, L., \& Huguet, P. (2008). Implicit theories of intelligence and IQ test performance in adolescents with generalized anxiety disorder. Behavior Research and Therapy, 46, 4, 529-536. 